\title{
La mythologie classique dans la littérature néo-latine. En hommage à Geneviève et Guy Demerson, études réunies et présentées par Virginie Leroux
}

\section{Dario Cecchetti}

\section{(2) OpenEdition Journals \\ Edizione digitale \\ URL: https://journals.openedition.org/studifrancesi/4620 \\ DOI: $10.4000 /$ studifrancesi.4620 \\ ISSN: 2421-5856 \\ Editore \\ Rosenberg \& Sellier}

\section{Edizione cartacea}

Data di pubblicazione: 1 avril 2012

Paginazione: 129-130

ISSN: 0039-2944

\section{Notizia bibliografica digitale}

Dario Cecchetti, «La mythologie classique dans la littérature néo-latine. En hommage à Geneviève et Guy Demerson, études réunies et présentées par Virginie Leroux», Studi Francesi [Online], 166 (I | LVI) | 2012, online dal 30 novembre 2015, consultato il 19 novembre 2021. URL: http://journals.openedition.org/ studifrancesi/4620 ; DOI: https://doi.org/10.4000/studifrancesi.4620

Questo documento è stato generato automaticamente il 19 novembre 2021.

\section{cc) (†)}

Studi Francesi è distribuita con Licenza Creative Commons Attribuzione - Non commerciale - Non opere derivate 4.0 Internazionale. 


\title{
La mythologie classique dans la littérature néo-latine. En hommage à Geneviève et Guy Demerson, études réunies et présentées par Virginie Leroux
}

\author{
Dario Cecchetti
}

\section{NOTIZIA}

La mythologie classique dans la littérature néo-latine. En hommage à Geneviève et Guy Demerson, études réunies et présentées par Virginie LEROUX, Clermont-Ferrand, Presses Universitaires Blaise Pascal, 2011 («Collection ERGA», 12), pp. 524.

1 I contributi qui raccolti sono stati presentati al III Congresso della Société Française d'Études Médio- et Néo-Latines (Clermont-Ferrand, 12-14 aprile 2005), Società che ha come vocazione di incoraggiare lo studio dell'Europa latina da Petrarca a Descartes. Salva restando la deplorazione per il ritardo (sei anni) con cui questi Atti vedono la luce, ritardo che per ragioni economiche diviene sempre più abituale nei convegni tale spesso da scoraggiare gli studiosi dal parteciparvi -, l'argomento scelto in omaggio di Geneviève e Guy Demerson, due pionieri che hanno aperto numerose piste alla ricerca sulla mitologia classica nel Cinquecento, è tra quelli che maggiormente concernono la poesia e le arti figurative nel Rinascimento. Si tratta, come ha ben sottolineato la curatrice Virginie Leroux nella sua presentazione, «di un campo assai vasto: quello delle chiavi interpretative applicato al mito, quello dei giochi intertestuali, quello degli enjeux encomiastici o teogonici, quello dell'adattamento di miti pagani a un contesto cristiano, quello dell'uso della mitologia nel quadro di una riflessione metapoetica, quello dell'appropriazione del mito come forma simbolica 
indissociabile dal lirismo e dell'invenzione di una mitologia personale» (p.32). L'insieme dei contributi, in gran parte trasversali alle letterature e alla produzione artistica europee, mette in evidenza l'importanza della letteratura neolatina nello sviluppo dell'Umanesimo e, soprattutto, nella lettura nuova dell'immaginario antico: e questo a partire da un approccio rigorosamente filologico, per cui il discorso si fonda su testi rari (editi o commentati) o su testi conosciuti, ma studiati sempre sulla base di un discorso attento alla 'parola'.

2 Questo discorso trasversale, sempre, per quanto concerne la cultura europea, ha una particolare rilevanza nei confronti della storia dell'Umanesimo e del Rinascimento francese. I contributi che interessano direttamente il francesista sono i seguenti: Philip FORD, Le mythe homérique d'Arès et Aphrodite dans la littérature néo-latine du XVI siècle (pp. 67-79); John NASSICHUK, Les divinités blessées: Cupidon guerrier dans une élégie de Louis de Masures (pp. 81-93); Virginie LEROUX, Achille et les mouches: du bon et du mauvais usage de la mythologie selon Jules-César Scaliger (pp.109-128); Sandra PRovINI, Mythe et historiographie dans le "De Neapolitana Fornoviensique victoria" de Fausto Andrelini (1496) (pp. 131-148); Sylvie LAIGNEAU-FONTAINE, Nicolas et les Muses: la mythologie, miroir de la poétique des "Nugae" (pp.149-163); Catherine LANGLOIS-PÉZERET, Enjeux littéraire et idéologiques des 'exempla' mythologiques dans la poésie néo-latine d'Étienne Dolet (pp. 165-183); Nathalie CATELLANI-DUFRÊNE, Les figures féminines de la mythologie antique dans les "Icones" de George Buchanan (pp. 185-196); Carine FERRADOU, Le modèle d'Iphigénie dans la tragédie de "Jephté" (1554) de George Buchanan (pp. 197-221); Perrine Galand (Les mythes intimes de Jean Salmon Macrin (pp. 315-340); Jean VIGNES, Baif panique (pp. 341-360); Émilie SERIS, La mort de Didon dans le "De casibus" de Boccace traduit par Laurent de Premierfait et enluminé par Fouquet (pp. 423-439).

3 La prima parte («Lectures de la mythologie antique») affronta il problema della lectio e della reductio del mito - e anche dell'approccio teorico all'immaginario classico - nei testi letterari e di poetica del Cinquecento, dimostrando attraverso analisi puntuali come una fabula mitologica sia ricostruita, in una determinata pièce, attraverso una rete di intertestualità fra fonti diverse (Nassichuk), oppure illustrando le prescrizioni sull'uso della mitologia classica a partire da un'ars poëtica rinascimentale (Leroux), o ancora ricostruendo la ricezione di un mito in una prospettiva trasversale e comparatistica di lettura della fabula (Ford). La seconda parte («Enjeux épidictiques et encomiastiques») indaga sullo sfruttamento in funzione epidittica ed encomiastica della mitologia antica e sulle problematiche connesse all'utilizzo di miti pagani in un contesto cristiano. È il caso di Fausto Andrelini, umanista italiano ma stabilito in Francia nell'entourage intellettuale della corte di Carlo VIII, che sulla falsariga di Virgilio e Stazio, da cui deriva stilemi e immaginario mitologico, celebra le imprese del re francese (Provini); oppure di Nicolas Bourbon che nelle sue Nugae integra la mitologia nel quotidiano e fa interagire ispirazione religiosa cristiana e mitologia pagana (Laigneau-Fontaine); o ancora di Étienne Dolet che utilizza gli exempla mitologici come specchio della sua composizione poetica e come professione di fede delle sue convinzioni politiche e, talvolta, metafisiche (Langlois-Pézeret); o infine di Gorge Buchanan che si serve nelle sue Icones di figure femminili della mitologia antica per rappresentare immagini morali e ritratti idealizzati di regine del Rinascimento (Catellani-Dufrêne), e nella tragedia Jephté opera una sintesi tra i personaggi biblici e quelli del mito di Ifigenia (Ferradou). La terza parte («Mythes intimes et créations mythologiques»), privilegiando una prospettiva intertestuale e iconica, analizza il 
processo di liberazione ermeneutica che sfocia nella creazione di miti intimi. In tale prospettiva l'utilizzazione sistematica da parte di Jean Salmon Macrin, nei suoi epitalami e nelle sue odi latine, di alcuni elementi mitologici selezionati in funzione di tratti specifici della sua autobiografia (nella fattispecie della sua storia amorosa) dimostra la trasformazione dei mitemi in elementi di un linguaggio privato (Galand). Sempre nella prospettiva dell'intimo', si dimostra come il riferimento a Pan nelle composizioni di Jean-Antoine de Baïf diventi emblema dell'ispirazione di Baïf, o meglio costruzione di una figura di se stesso (Vignes). La quarta parte («Les arts figurés») si interessa, in saggi consacrati essenzialmente all'arte italiana, dell'immaginario mitologico nella pittura, dal punto di vista iconologico come da quello teorico concernente l'invenzione pittorica. Abbiamo in questa sezione un interessante saggio di lettura iconica, trasversale e intertestuale, sul mito di Didone, saggio che coinvolge i rapporti culturali tra Italia e Francia e l'intertestualità tra letteratura e pittura (Seris). 